\title{
Multiple mechanisms of early plant community assembly with stochasticity driving the process
}

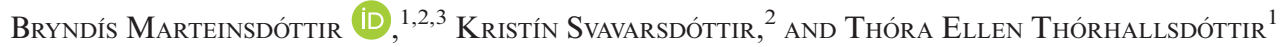 \\ ${ }^{1}$ Institute of Life and Environmental Sciences, University of Iceland, Sturlugata 7, 101 Reykjavik, Iceland \\ ${ }^{2}$ The Soil Conservation Service of Iceland, Keldnaholt, 112 Reykjavik, Iceland
}

\begin{abstract}
Initial plant establishment is one of the most critical phases in ecosystem development, where an early suite of physical (environmental filtering), biological (seed limitation, species interactions) and stochastic factors may affect successional trajectories and rates. While functional traits are commonly used to study processes that influence plant community assembly in late successional communities, few studies have applied them to primary succession. The objective here was to determine the importance of these factors in shaping early plant community assembly on a glacial outwash plain, Skeiðarársandur, in SE Iceland using a trait based approach. We used data on vascular plant assemblages at two different spatial scales (community and neighborhood) sampled in 2005 and 2012, and compiled a dataset on seven functional traits linked to species dispersal abilities, establishment, and persistence for all species within these assemblages. Trait-based null model analyses were used to determine the processes that influenced plant community assembly from the regional species pool into local communities, and to determine if the importance of these processes in community assembly was dependent on local environment or changed with time. On the community scale, for most traits, random processes dominated the assembly from the regional species pool. However, in some communities, there was evidence of non-random assembly in relation to traits linked to species dispersal abilities, persistence, and establishment. On the neighborhood scale, assembly was mostly random. The relative importance of different processes varied spatially and temporally and the variation was linked to local soil conditions. While stochasticity dominated assembly patterns of our early successional communities, there was evidence of both seed limitation and environmental filtering. Our results indicated that as soil conditions improved, environmental constraints on assembly became weaker and the assembly became more dependent on species availability.
\end{abstract}

Key words: environmental filtering; outwash plain; primary succession; seed limitation; stochasticity; vegetation development.

\section{INTRODUCTION}

Initial plant establishment in early ecosystem assembly has been identified as one of the most critical phases in ecosystem development (Walker and del Moral 2003). During this first stage, colonization is often limited by unfavorable local environmental conditions (Titus and del Moral 1998, Jones and del Moral 2009), seed availability (Marteinsdóttir et al. 2010, Makoto and Wilson 2016) or lack of facilitating species (Callaway 1995). More recently, the importance of random colonization and thus stochasticity during this phase, has become evident (Marteinsdóttir et al. 2013, Zaplata et al. 2013, Ulrich et al. 2016). As succession advances, abiotic conditions improve (Buma et al. 2017) and species interactions, such as competition, increasingly influence establishment (Chapin et al. 1994). Thus, processes determining plant community assembly

Manuscript received 16 March 2017; revised 22 July 2017; accepted 4 October 2017. Corresponding Editor: Jeannine M. Cavender-Bares.

${ }^{3}$ E-mail: bryndis@land.is will change over succession. The early colonizers are often characterized as species with good dispersal abilities that can establish and persist in harsh environments, while late species are usually good competitors (Connell and Slatyer 1977). As early colonizers may direct subsequent development, knowledge of the processes that determine early colonization is crucial for understanding the nature of plant community assembly (Fukami 2015, Buma et al. 2017) and for managing highly degraded ecosystems and newly created substrates (Walker and del Moral 2009, Walker et al. 2009, del Moral 2010).

Trait-based null model analyses are commonly used to study the processes that influence plant community assembly in late successional communities (e.g. Götzenberger et al. 2012). However, only a limited number of studies have been conducted in early successional habitats (Schleicher et al. 2011, Raevel et al. 2012, Ulrich et al. 2014) and they are mostly restricted to small disturbed sites. In these studies, observed community trait assembly is compared to assemblages generated by drawing species at random from the available species pool. If the observed community trait assembly does not differ from the 
random draw, species assembly is seen as a neutral process in relation to that trait. If species assembly depends on species traits, then non-neutral processes like environmental filtering, seed limitation, or species interactions are implicated (Götzenberger et al. 2012). Separation of the non-neutral processes is then determined on the basis of the trait studied, the scale of the assembly and whether there is trait-convergence or divergence. On the community scale, convergence towards species with traits that enhance establishment indicates environmental filtering (Weiher and Keddy 1995), whereas convergence towards good dispersal abilities indicates seed limitation (Marteinsdóttir and Eriksson 2014). The influence of species interactions on assembly is however mostly detected when the assembly is studied on a small (i.e., neighborhood) scale (Swenson et al. 2006, Mouquet et al. 2012, Perronne et al. 2017) even though trait divergence at the community scale is usually interpreted as the effect of species interactions (Götzenberger et al. 2012, de Bello et al. $2013 b$ ). Trait divergence (on all scales) has traditionally been linked to competition, as species with similar traits are expected to have similar resource requirements and thus compete more intensely (i.e., limiting similarity, Lavorel et al. 2007, Violle and Jiang 2009). However, it has also been proposed that facilitation among species can generate the same pattern (Spasojevic and Suding 2012). Trait-convergence at the neighborhood scale for competition traits implies that only species with good competition abilities (e.g., tall stature) will survive (Shipley 1993, Mayfield and Levine 2010, de Bello et al. 2012). Alternatively, it has been suggested that by being similar enough, species may escape the rule of limiting similarity and coexist (Scheffer and van Nes 2006), causing convergence in traits related to establishment and persistence. Integrating trait-based analyses with primary successional studies provides a powerful tool to determine the processes that shape early plant community assembly and how they change with local environment and seral stages (Meiners et al. 2014, Chang and HilleRisLambers 2016).

Here we examined the trait-based plant community assembly from a regional species pool into early primary successional communities. Our aim was to determine how seed limitation, environmental filtering, species interactions and stochasticity shape early plant community assembly. We used data on vascular species presence and abundance on different spatial scales on Skeiðarársandur, a $1,000 \mathrm{~km}^{2}$ glacier outwash plain in SE-Iceland. With its huge size, minimal human impact, and currently rapid changes due to greatly reduced disturbance regimes as a consequence of glacier retreat, Skeiðarársandur offers an outstanding opportunity to test general theories on early community assembly. The sandur plain is at an early stage of succession, with mostly $<10 \%$ vegetation cover (Kofler 2004). Species pools were determined at three spatial scales; the regional scale, community scale, and neighborhood scale and species assembly studied both at the community and neighborhood scales. Trait-based null model analyses were applied to determine which processes control species assembly. We also examined how local environmental conditions and seral stage influenced the assembly process. We focused on three questions: (1) How are species assembled into local communities from the regional species pool? (2) Is species assembly dependent on local environmental conditions? (3) Does the importance of these processes in community assembly change with time?

In our study, we expect community assembly to be highly influenced by neutral processes as previous studies have indicated that stochastic events are important for plant colonization (Marteinsdóttir et al. 2010, 2013, Ulrich et al. 2016). More species are however able to colonize sites with ameliorated conditions, thus assembly should be influenced by the local environment. As plant establishment is likely to be very slow under harsh conditions and in areas far from the nearest seed source (Marteinsdóttir et al. 2013, Makoto and Wilson 2016), we expect only minor changes to occur over the study period.

\section{Methods \\ Study site}

The study was conducted on Skeiðarársandur (W 17²12; N 6357), a sandy, flat, and homogeneous glacial outwash plain in front of Skeiðarárjökull, the largest outlet glacier of Vatnajökull icecap, SE-Iceland (Fig. 1). We excluded the west and east marginal areas (west of Gígjukvísl river and east of Skeiðará river path) resulting in a research area of $\sim 400 \mathrm{~km}^{2}$. At present, it is mostly at an early successional stage with $75 \%$ of the area having $<10 \%$ vegetation cover, and $15 \%$ with $>50 \%$ cover. The better vegetated areas are moss heathland, with herbs and a few small birch and willow shrubs (Kofler 2004). The climate on Skeiðarársandur is maritime, with cool summers and mild winters. Temperature and precipitation values from 1949 to 2012 were obtained from the nearest weather station Fagurhólsmýri $\left(65^{\circ} 53^{\prime} \mathrm{N}, 16^{\circ} 39^{\prime} \mathrm{W}\right)$. The mean annual air temperature was $4.9^{\circ} \mathrm{C}( \pm 0.07)$ and the mean summer (June-August) temperature $9.9^{\circ} \mathrm{C}( \pm 0.07)$. Mean annual and summer precipitation was $1,814 \mathrm{~mm}( \pm 33.8)$ and $130 \mathrm{~mm}( \pm 5.1)$, respectively (Icelandic Meteorological Office, unpublished data). The growing season at Skeiðarársandur generally lasts from approximately mid-May to early September (personal observation). For the past $\sim 60 \mathrm{yr}$, the sandur has been a summer grazing land (from early June until September) for ca 200 ewes plus lambs (Búnaðarsamband Suðurlands, personal communication).

\section{Vegetation sampling}

In the summers of 2004-2005, 47 permanent plots $(25 \times 25 \mathrm{~m})$ were laid out on a $2 \mathrm{~km}$ grid, in the upper part of Skeiðarársandur, covering an area around $140 \mathrm{~km}^{2}$. All plots were in flat areas, spanning a narrow altitudinal gradient ( $\sim 50-100$ m.a.s.l.) and experienced very similar climate. In 2004, 10 plots were laid out and in 


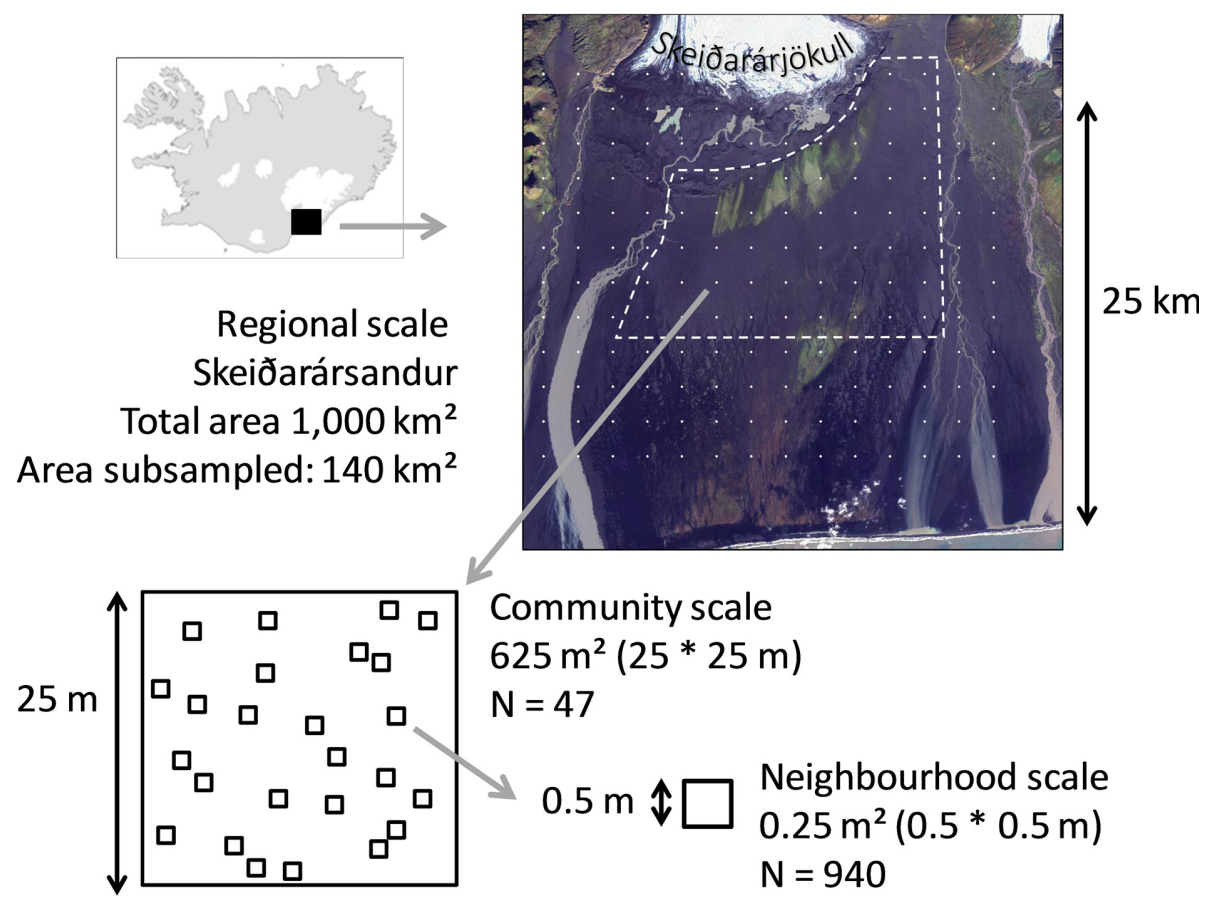

FIG. 1. The study design on Skeiðarársandur. The regional scale contains the whole outwash plain. Within the study area, $4725 \times 25 \mathrm{~m}$ plots were laid out evenly, $2 \mathrm{~km}$ apart at the upper area of Skeiðarársandur. Within each plot (community scale) $20,0.5 \times 0.5 \mathrm{~m}$ quadrats (neighborhood scale) were laid out randomly.

2005, an additional 37 plots. In each plot, vascular species presence was recorded and their cover estimated in 20 randomly placed quadrats $(50 \times 50 \mathrm{~cm}$, a total of 940 quadrats; Fig. 1). A modified Braun-Blanquet scale with eight cover classes $(<1 \% ; 1-5 \% ; 5-10 \% ; 10-15 \% ; 15-$ $25 \% ; 25-50 \% ; 50-75 \% ;>75 \%$; van der Maarel 1979) was used for species cover estimation. In addition, all species inside the $25 \times 25 \mathrm{~m}$ plot were recorded. We did not distinguish between the two sampling years, 2004 and 2005, and refer to those samples as year 2005 hereafter. In 2012 the vegetation sampling was repeated in 45 out of the 47 permanent plots as two plots were inaccessible.

We defined species pools at three different scales; neighborhood, community, and regional (Fig. 1). Neighborhood scale included all species found in any quadrat within a plot (20 quadrats per plot, $\mathrm{N}=940$ ) and community scale all species within a $25 \times 25 \mathrm{~m}$ plot $(\mathrm{N}=47)$. The mean species cover in the 20 quadrats within a plot was used as a measure of community scale species abundance. Species not recorded in the quadrats but present at a plot level, were assigned an arbitrary plot abundance of $0.025 \%$. The regional species pool $(\mathrm{N}=1)$ was determined using two different approaches. First, the observed species pool (ObsPool) is the total of 80 species present in the 47 study plots. Second, the extended species pool (ExtPool) was constructed by adding to the ObsPool other species recorded on Skeiðarársandur, either from other studies (Póra Ellen bórhallsdóttir, Kristín Svavarsdóttir, Jamie Ann Martin, and Ólöf Birna Magnúsdóttir, unpublished data) or the national plant registry from the Icelandic Institute of Natural History. Only species that should be able to grow under the environmental conditions in our study plots were included in the ExtPool. The ExtPool does therefore account for the "dark diversity" (sensu Pärtel et al. 2011), i.e., species in the region pool that can grow under the environmental conditions at a site, here Skeiðarársandur, but are missing. We did however take a conservative approach when choosing species from the national plant registry as simulation studies have shown that it is better to underestimate than overestimate the species pool (de Bello et al. 2012). In total, 147 vascular plant species were in the ExtPool (Appendix S1: Table S1).

\section{Soil sampling}

Soil samples were collected from 45 out of the 47 permanent plots in 2005. Within each plot, 10 soil cores were sampled to a depth of $5 \mathrm{~cm}$. The 10 samples were combined prior to analyses. Soils were dried at $\sim 60^{\circ} \mathrm{C}$. Organic carbon and nitrogen were measured using dry combustion (Vario MAX C/N-Macro Elemental Analyzer). Samples were checked for moisture content at the time of analyses and results adjusted accordingly. Soil $\mathrm{pH}$ was measured in water (1:5 soil-water ratio) and in $1 \mathrm{~mol} / \mathrm{L} \mathrm{KCl}$ solution.

\section{Functional traits}

Data on seven traits linked to dispersal abilities, establishment, and persistence were obtained from the 
TRY - trait database (Fitter and Peat 1994, Kühn et al. 2004, Kew 2008, Kleyer et al. 2008, Green 2009, Klimešová and de Bello 2009, Kattge et al. 2011), publications (Hempel et al. 2013) and the local flora (Stefánsson 1948, Kristinsson 2010). Trait selection was based on two considerations: (1) the ecosystem processes that they link to and (2) availability of data for the species in our extended species pool. Traits linked to dispersal abilities were seed mass and dispersal syndrome (i.e., wind, water, or animal dispersed or unassisted dispersal). Traits influencing establishment were seed mass, specific leaf area (SLA) and mycorrhizal association. Traits associated with persistence were height, lateral spread and first month of flowering (FMF). For more details on the traits and discussion on their selection, see Appendix S2. If more than one value was cited for a given trait in the data-base, we used the median. For most traits, values from northern Europe and northern North America were used. Trait data availability was high, ranging from $83 \%$ (dispersal syndrome) to $100 \%$ (mycorrhizal association, height and lateral spread) for species in the regional species pool (Appendix S2: Table S1).

\section{Statistical analyses}

We explored community assembly at two spatial scales (neighborhood and community) at two times (2005 and 2012). We calculated trait functional diversity (FD) and community trait mean (CM), and applied randomization models to determine the influence of seed limitation, environmental filtering and species interactions on the assembly process.

Various indices are available for estimating community functional diversity (reviewed by Mouchet et al. 2010, Schleuter et al. 2010). Here, we used the mean phylogenetic distance (MPD) to calculate the mean pairwise trait distance separating species in a community. While this index was first developed for phylogenetic distances, it is frequently used for plant traits. It was chosen as it is unaffected by species richness and can take into account species abundance but also works well with presence-absence data. In addition, it can handle any number of traits (Webb et al. 2002, Pavoine and Bonsall 2011, de Bello et al. 2012). Even though the MPD index can include multiple traits, we calculated it for each trait separately as different traits might show different patterns and combining them could give the illusion of neutral assembly, e.g., when one trait shows convergence and another divergence (Grime 2006, Swenson and Enquist 2009). For continuous traits, Euclidean distance was used and Gower's distance for categorical traits. Prior to analysis, values of categorical traits were transformed to numerical values. For dispersal syndrome, the mean dispersal distance for each syndrome was used. For lateral spread the mean of each group was calculated. FMF values were based on the month of the year and mycorrhizal type was given 0 if the species was marked as non-mycorrhizal and 1 if it can have mycorrhizal associations.
For each plot (community scale) and quadrat (neighborhood scale), 999 random vegetation assemblages were generated by randomly drawing species from the pool into the assemblages, until species richness of the observed plot or quadrat was reached. All species had the same probability of being chosen. On the neighborhood scale, species were drawn from a pool consisting of all species in the local community. On the community scale, analyses were run both with the ObsPool and ExpPool. The outcome of analyses using ObsPool and ExpPool did not differ, so only results using ExpPool are reported here. Results from the ObsPool are in Appendix S3. For each observed and randomized assembly, FD and CM were calculated for the seven traits. We calculated the standardized effect size (SES) for each plot and quadrat by comparing the observed FD $\left(\mathrm{FD}_{\mathrm{SES}}\right)$ or CM $\left(\mathrm{CM}_{\mathrm{SES}}\right)$ to 999 values generated by randomization (Gotelli and McCabe 2002, Kembel et al. 2010). SES was calculated as:

$$
\mathrm{SES}=\frac{\text { Observed value }- \text { mean }(\text { random values })}{\mathrm{SD}(\text { random values })}
$$

where SD stands for standard deviation. Positive FD $_{\mathrm{SES}}$ values indicate trait divergence and negative values convergence. Positive $\mathrm{CM}_{\mathrm{SES}}$ suggests higher and negative $\mathrm{CM}_{\text {SES }}$ lower mean trait values than expected by random. The deviation from random was denoted significant if the SES value was higher than 1.96 or lower than -1.96 (ca 95\% upper and lower confidence intervals). Before calculations, seed mass and height were log transformed for normalization. Only plots and quadrats with more than one species present having a value for that particular trait were included in the analyses, giving a sample size of 44-47 plots on the community scale and 526-630 quadrats on the neighborhood scale for each trait. Analyses based on species presence and species abundance gave similar outcome so only results based on species presence are presented in the result section of this paper. Results based on species abundance, where the mean nearest trait distance for each species (MPD) and the community mean (CM) was weighted by species abundance can be found in Appendix S3.

Various null-model approaches have been used to study the processes determining plant community assembly. They have at times been criticized for their weak abilities to detect deviation from randomness (Götzenberger et al. 2016, Miller et al. 2017). Thus, to further strengthen our conclusions, we also analyzed the data with two models from the picante package (Kembel et al. 2010) recommended by Götzenberger et al. (2016). For trait-divergence, we used randomization that swaps abundances across all species occurring in the observed species pool and for trait-convergence, we used a model that exchanges species abundances across plots. These models gave similar results as our other randomization tests (Appendix S3).

To explore whether the assembly process was dependent on local community environmental conditions, 
linear models were applied with community $\mathrm{FD}_{\mathrm{SES}}$, $\mathrm{CM}_{\mathrm{SES}}$ or species richness as the dependent variable, and community soil conditions the independent variable. There was a strong correlation among the measured soil variables (Appendix S4). Therefore, soil carbon was used as an indicator for plot soil conditions. Soil carbon was $\log$ transformed before analyses. Environmental patterns and trait filtering were similar in 2005 and 2012 so only data from 2012 are shown. Data from 2005 are reported in Appendix S3. To determine how plant community assembly changed over time, community FD and CM were compared between 2005 and 2012 using a paired $t$-test or paired Wilcoxon test, if data were non-normally distributed.

\section{Results}

\section{Functional trait filtering from the species pool}

On the community scale, species were mostly assembled into communities by neutral processes (Fig. 2). Trait convergence for seed mass was observed in $36 \%$ of the communities (Fig. 2A) and 11\% of communities had higher average seed mass than expected from random assembly (Fig. 2B). Mean FMF was earlier than expected by random in $11 \%$ and greater mean lateral spread abilities in $22 \%$ of communities (Fig. 2B). On the neighborhood scale, there was little indication of deterministic assembly with most quadrats having neutral assembly for all traits (Table 1).

\section{Spatial patterns}

Despite the apparent homogeneity of the sandur, communities varied considerably, both physically and in species richness and cover (Table 2). Trait based community assembly was affected by local soil conditions. With improved soil conditions, FD of communities changed (1) from having near neutral assembly in relation to seed mass, to increasing trait convergence; (2) from trait divergence towards trait convergence for lateral spread; (3) from trait convergence towards trait divergence for height and FMF; and (4) from trait convergence toward neutral assembly for dispersal syndrome (Fig. 3). In addition, for some traits the mean community values were dependent on soil conditions. Community mean seed mass and lateral spread declined towards the expected mean from neutral assembly, the mean FMF shifted toward lower values than expected and dispersal syndrome from lower values towards neutral assembly (Fig. 4).
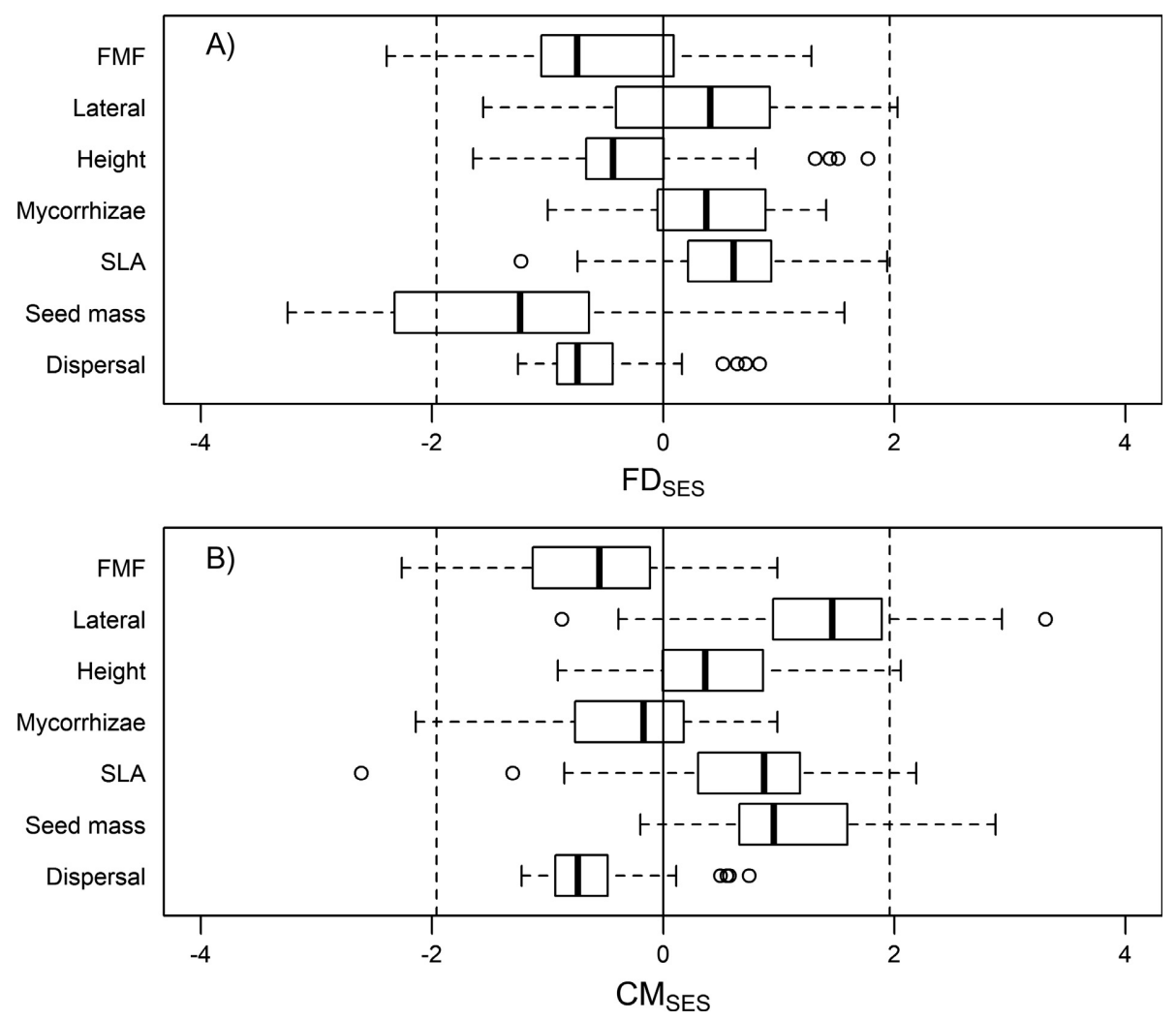

FIG. 2. Standard effect size (SES) of (A) functional diversity ( $\left(\mathrm{FD}_{\mathrm{SES}}\right)$ and (B) community mean $\left(\mathrm{CM}_{\mathrm{SES}}\right)$ of seven different traits in 45 communities on Skeiðarársandur in 2012. Dotted lines indicate the $95 \%$ confidence limits, values outside those limits deviate significantly from random. 
TABLE 1. Number of quadrats in 2012 having trait assembly that deviated significantly from a neutral assembly based on models run on species presence data on Skeiðarársandur.

\begin{tabular}{lccccccc}
\hline \hline & $\begin{array}{c}\text { Dispersal } \\
\mathrm{N}=556\end{array}$ & $\begin{array}{c}\text { Seed mass } \\
\mathrm{N}=608\end{array}$ & $\begin{array}{c}\text { SLA } \\
\mathrm{N}=616\end{array}$ & $\begin{array}{c}\text { Mycorrhizae } \\
\mathrm{N}=616\end{array}$ & $\begin{array}{c}\text { Height } \\
\mathrm{N}=616\end{array}$ & $\begin{array}{c}\text { FMF } \\
\mathrm{N}=608\end{array}$ & $\begin{array}{c}\text { Lateral } \\
\mathrm{N}=616\end{array}$ \\
\hline FD random & 529 & 578 & 598 & 614 & 591 & 589 & 595 \\
FD convergence & 24 & 17 & 4 & 1 & 21 & 19 & 2 \\
FD divergence & 3 & 13 & 14 & 3 & 4 & 0 & 19 \\
CM random & 531 & 592 & 577 & 605 & 593 & 603 & 569 \\
CM higher & 0 & 2 & 10 & 10 & 4 & 1 & 0 \\
CM lower & 25 & 14 & 29 & 1 & 19 & 4 & 47
\end{tabular}

Notes: Random: neutral assembly; FD convergence: trait convergence in functional diversity; FD divergence: trait divergence in functional diversity; CM higher: Higher community mean trait values than expected by random; CM Lower: Lower community mean trait values than expected by random. $\mathrm{N}=$ number of quadrats included in the analyses. Dispersal = dispersal syndrome, seed mass $=$ average seed mass, SLA $=$ average specific leaf area, Mycorrhizae $=$ grows $w i t h /$ without mycorrhizae, Height $=$ average height, FMF = First month of flowering and Lateral $=$ average lateral spread.

\section{Temporal patterns}

In general, the functional trait assembly from the species pool was similar in 2005 and 2012 (Appendix S3). However, there were some clear changes in the community structure. Mean community vascular species richness increased between years, from $16( \pm 1.5$ Standard Error) in 2005 to 21 ( $\pm 1.8 \mathrm{SE})$ in 2012. Community FD was lower for mycorrhizae and higher for FMF in 2012 than in 2005. Furthermore, CM for lateral spread decreased and there was a marginally higher proportion of mycorrhizal species over time (Table 3).

\section{DisCUSSION}

Plant community assembly on Skeiðarársandur is shaped by stochasticity, environmental conditions and species availability. While assembly from the regional species pool into local communities is mostly neutral, there were directional changes observed in the assembly influenced by the local environment and the seral stage.

\section{Community assembly from the regional species pool}

Neutral community assembly was by far the most common pattern observed in this study, both on the community and neighborhood scale, indicating that during primary succession on Skeiðarársandur, plant community assembly is highly influenced by stochasticity. Generally, neutral community assembly is considered to be strongest in communities that are dominated by colonization (Zillio and Condit 2007). Deterministic processes are traditionally thought to dominate early successional stages (Connell and Slatyer 1977, del Moral and Bliss 1993, Mori et al. 2013) but the number of studies reporting the dominance of stochasticity in primary succession is increasing (del Moral et al. 1995, Marteinsdóttir et al. 2010, Schleicher et al. 2011). At sites like Skeiðarásandur with low soil nutrient status, limited seed rain and low seedling survival (Marteinsdóttir 2007, Marteinsdóttir et al. 2010), a successful colonization requires a sequence of favorable events: A seed has to disperse to the site and land on a suitable microsite and at a time with favorable conditions for germination and early growth. Thus colonization is highly affected by stochastic factors like weather and rare historical events. As the first colonizers may direct subsequent development (Fukami 2015), these early stochastic events will shape the trajectory of late community assembly.

The power of trait-assembly models to detect deviation from randomness has been questioned (Götzenberger et al. 2016, Miller et al. 2017). To address these concerns we accounted for dark diversity in our regional species pool. We also studied assembly at both the

TABLE 2. Minimum ( $\min$ ), maximum ( $\max$ ) and median species richness, vegetation cover and soil measurements in the 47 (45 in 2012) study communities on Skeiðarársandur. Vegetation data were collected in 2005 and 2012 and soil data in 2005.

\begin{tabular}{|c|c|c|c|c|c|c|}
\hline & \multicolumn{3}{|c|}{2005} & \multicolumn{3}{|c|}{2012} \\
\hline & Min & Max & Median & Min & Max & Median \\
\hline Species richness & 3 & 43 & 13 & 3 & 51 & 18 \\
\hline Vegetation cover & 0.2 & 96.7 & 3.15 & 0.4 & 100.0 & 3.0 \\
\hline Vascular plant cover & 0.05 & 69.25 & 2.5 & 0.3 & 55.8 & 2.2 \\
\hline Soil carbon $(\%)$ & 0.01 & 1.14 & 0.05 & - & - & - \\
\hline Soil nitrogen (\%) & 0.01 & 0.07 & 0.01 & - & - & - \\
\hline Soil C/N & 1.8 & 24.0 & 5.9 & - & - & - \\
\hline Soil pH & 4.8 & 6.7 & 5.5 & - & - & - \\
\hline
\end{tabular}



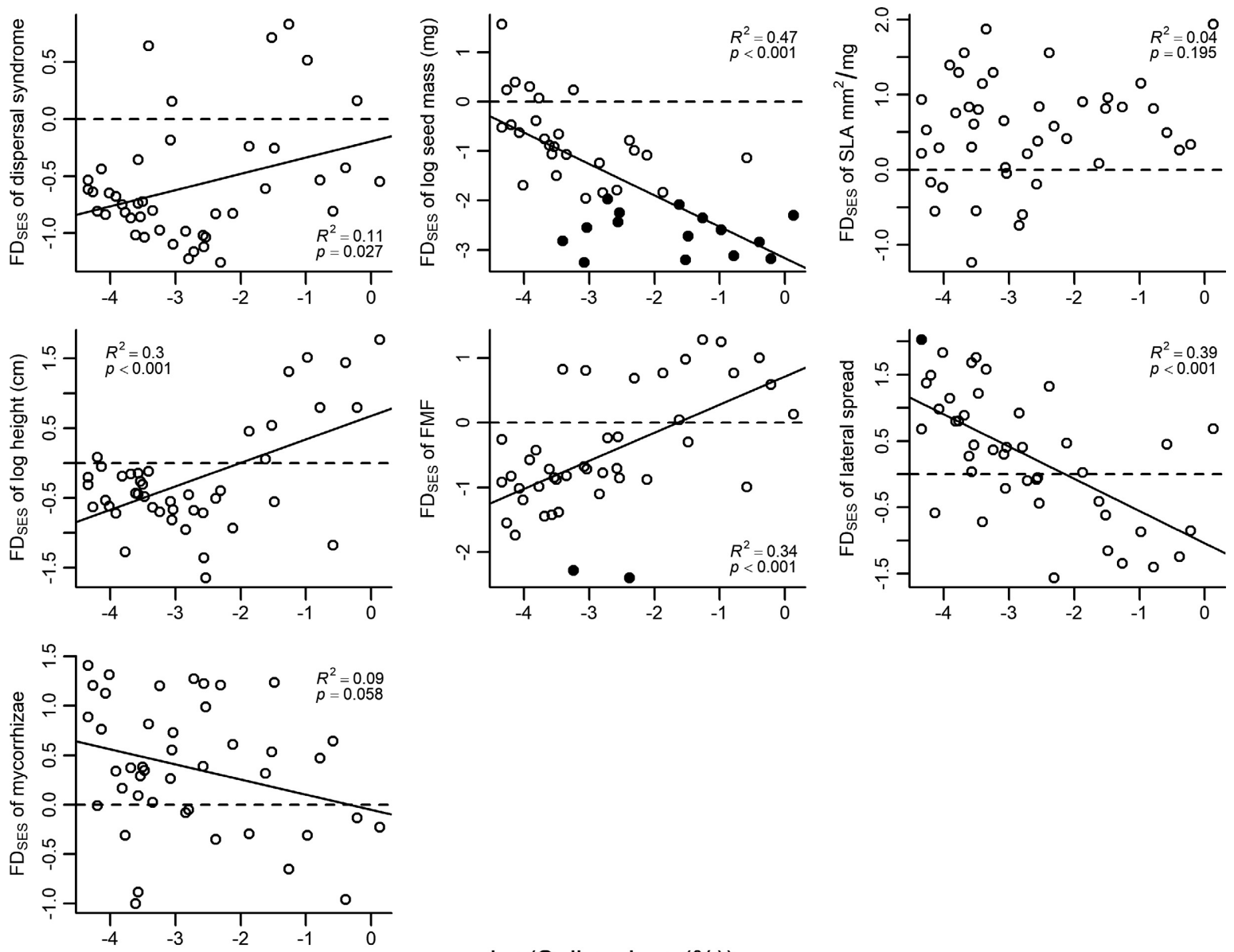

\section{$\log ($ Soil carbon $(\%))$}

FIG. 3. Relationship between standard effect size of community scale functional diversity $\left(\mathrm{FD}_{\mathrm{SES}}\right)$ and log (soil carbon) percentage at Skeiðarársandur $(\mathrm{N}=45)$. Solid lines represent the regression lines from linear models. The dotted line is the 0 line, indicating neutral assembly. Black circles indicate plots with significant trait convergence or divergence. Open circles represent plots that do not differ from neutral assembly. SLA = specific leave area, FMF = First month of flowering.

community scale and the neighborhood scale, allowing us to better detect assembly processes that work on different spatial scales. Although, the importance of both dark diversity (Pärtel et al. 2011, de Bello et al. 2012) and different spatial scales (Perronne et al. 2017) in assembly studies is acknowledged, few studies have included those. In addition, we ran various null model analyses to verify our results. While there were some minor differences in the results of these models, all supported our conclusion that stochasticity dominates the assembly process at our study site.

In addition to neutral assembly, we found more restricted range of seed mass within the local communities than in the regional pool in approximately one-third of the communities and selection for species with greater lateral spread occurred in over $20 \%$ of communities. Under the harsh environmental conditions on Skeiðarársandur, where seedling recruitment is low, large seeds or efficient lateral spread, will enhance the probability of establishing and persisting (Turnbull et al. 1999, Cornelissen et al.
2003). However, large seeds may also limit dispersal ability (Turnbull et al. 1999, Leishman 2001), thus the species that establish in the local communities are those with small enough seeds to overcome the seed limitation but large enough to overcome the establishment limitation.

Only few studies have used trait-based community assembly to study primary succession, and all support our results of the importance of stochasticity (Schleicher et al. 2011, Raevel et al. 2012, Ulrich et al. 2014). The influence of deterministic processes in assembly is often emphasized in studies on secondary and late successional communities (e.g., Marteinsdóttir and Eriksson 2014, Zhang et al. 2015), even though neutral processes often play a large role (Götzenberger et al. 2012). This indicates that in these communities, stochasticity is important but to a lesser degree. Some of this stochasticity might be a legacy from the initial steps of assembly in the ecosystem. An improved knowledge of the processes determining those first steps might be the key for understanding better species assembly in late successional communities. 

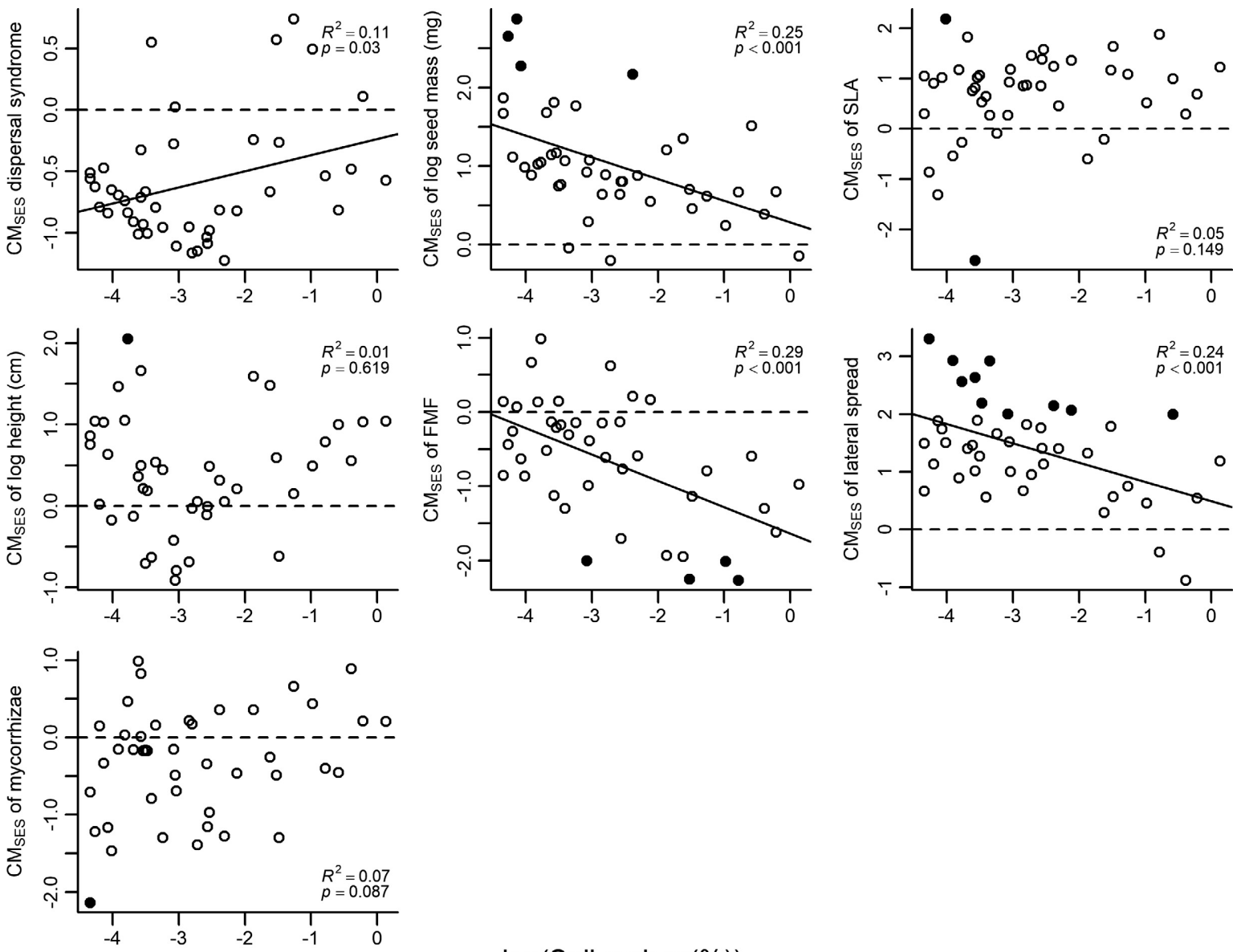

\section{$\log ($ Soil carbon(\%))}

FIG. 4. Relationship between standard effect size of community mean trait value $\left(\mathrm{CM}_{\mathrm{SES}}\right)$ and log (soil carbon) percentage on Skeiðarársandur $(\mathrm{N}=45)$. Solid lines represent the regression lines from linear models. The dotted line is the 0 line, indicating neutral assembly. Black circles indicate plots with significantly higher or lower mean trait values than expected from neutral assembly. Open circles represent plots with neutral assembly. SLA $=$ specific leave area, FMF $=$ First month of flowering.

\section{Influence of environmental conditions}

Trait assembly from the regional species pool into local communities on Skeiðarársandur was correlated with local soil conditions for most traits, supporting the scenario that assembly is, at least partly, driven by local environmental conditions. Species richness also increased with improved soil fertility.

It has been hypothesized that functional diversity of traits increases as establishment becomes less restricted by local environmental conditions (Mouchet et al. 2010, Mason et al. 2012). While studies have found a positive relationship between functional diversity and soil nutrients (Bernhardt-Römermann et al. 2010, Ulrich et al. 2014), other studies have shown decreased functional diversity under more benign conditions (de Bello et al. $2013 a$ ) or found these patterns to be trait specific (Spasojevic and Suding 2012). Here, the effect was trait specific, with functional diversity decreasing (for seed mass and lateral spread), increasing (height, dispersal syndrome and FMF) or showing no pattern (SLA, mychorrhizal syndrome) with better soil conditions. In addition, seed mass, FMF and lateral spread were negatively correlated with soil conditions and dispersal syndrome positively.

Nutrient levels on Skeiðarársandur are very poor (Table 2) and seed establishment is rare in the sparsely vegetated part (Marteinsdóttir et al. 2010). As soil conditions improved, environmental constraints on establishment become in general weaker, increasing the establishment success of plants. This enables species with low seed mass to establish and reduces the advantage clonal plants have for persisting. Better conditions will also increase the density of suitable microsites allowing species with contrasting resource requirements to coexist (Chesson 2000, Adler et al. 2013) which can increase the functional diversity for traits linked to species persistence and competition. In addition, with succession the complexity of food webs increases, which may indirectly increase the number of possible dispersal agents (Chang et al. 2014), making FD of dispersal syndrome similar to what is found in random communities. 
TABle 3. Mean ( \pm standard error) of community species richness, community functional diversity (FD) and community trait mean $(\mathrm{CM})$ in 2005 and 2012.

\begin{tabular}{|c|c|c|c|}
\hline & 2005 & 2012 & $P$-value \\
\hline Species richness & $15.9 \pm 1.49$ & $20.7 \pm 1.78$ & $* * *$ \\
\hline \multicolumn{4}{|l|}{ FD } \\
\hline Log seed mass (mg) & $1.6 \pm 0.06$ & $1.6 \pm 0.06$ & NS \\
\hline Log height $(\mathrm{cm})$ & $0.8 \pm 0.02$ & $0.8 \pm 0.02$ & NS \\
\hline SLA $\left(\mathrm{mm}^{2} / \mathrm{mg}\right)$ & $9.4 \pm 0.21$ & $9.3 \pm 0.22$ & NS \\
\hline Lateral spread (cm) & $0.4 \pm 0.01$ & $0.38 \pm 0.01$ & NS \\
\hline Mycorrhizae & $0.38 \pm 0.019$ & $0.35 \pm 0.015$ & $*$ \\
\hline Dispersal syndrome & $0.02 \pm 0.005$ & $0.02 \pm 0.006$ & NS \\
\hline FMF & $0.13 \pm 0.009$ & $0.15 \pm 0.007$ & $*$ \\
\hline \multicolumn{4}{|l|}{$\mathrm{CM}$} \\
\hline Log seed mass (mg) & $(-) 0.8 \pm 0.13$ & $(-) 1.0 \pm 0.07$ & NS \\
\hline Log height $(\mathrm{cm})$ & $2.9 \pm 0.03$ & $2.9 \pm 0.03$ & NS \\
\hline SLA $\left(\mathrm{mm}^{2} / \mathrm{mg}\right)$ & $20.4 \pm 0.40$ & $20.4 \pm 0.37$ & NS \\
\hline Lateral spread $(\mathrm{cm})$ & $0.117 \pm 0.005$ & $0.108 \pm 0.004$ & $*$ \\
\hline Mycorrhizae & $0.76 \pm 0.015$ & $0.78 \pm 0.012$ & $(*)$ \\
\hline Dispersal syndrome & $3.0 \pm 0.53$ & $2.4 \pm 0.46$ & NS \\
\hline FMF & $5.90 \pm 0.019$ & $5.88 \pm 0.016$ & NS \\
\hline
\end{tabular}

Notes: $P$ values show the significance of the differences between 2005 and 2012 data, based on $t$-test or Wilcoxon test. NS $=$ non significant $(P>0.10),(*)$ near significant $(0.10>P>0.05), * P<0.05, * * * P<0.001$.

Changes in species interactions with environmental amelioration (and higher species richness) can also influence assembly. Competitive exclusion can bring either limiting similarity (Lavorel et al. 2007, Violle and Jiang 2009) or trait convergence as only species with good competitive availability can establish (Shipley 1993, Mayfield and Levine 2010, de Bello et al. 2012). Furthermore, increased facilitation will lead to trait divergence (Spasojevic and Suding 2012). As vegetation cover on Skeiðarársandur is mostly low and the communities are still at very early successional stages, it is unlikely that species competition influences the assembly yet. While evidence of species interactions affecting the assembly has been found in early succession elsewhere (Ulrich et al. 2016), competive exclusion is usually only evident in fertile plots (Schleicher et al. 2011) and in later seral stages (Chapin et al. 1994). However, it cannot be ruled out that facilitation dependent on soil conditions are influencing the patterns observed.

\section{Changes over time}

There were only minor changes in the trait-assembly from the regional species pool into local communities between 2005 and 2012. However, species richness did increase significantly over time and community assembly differed between years for some traits, indicating that there were deterministic changes in the assembly process.

In primary succession, communities accumulate species over time (Hodkinson et al. 2003, del Moral and Magnússon 2014, Ulrich et al. 2014) and here average species richness per community increased from 16 to 21 species over 7 yr. Differences in community assembly between years were mostly consistent with changes seen along the soil carbon gradient. We detected an increase in diversity of first month of flowering and a decrease in community mean lateral spread with time, factors that may reflect improvement of environmental conditions during succession (Vilmundardóttir et al. 2015a, b) and accumulation of species over time. Furthermore, trait convergence in mycorrhizal association, with a marginal increase in the proportion of mycorrhizal species occurred. This may reflect an increase in the proportion of mycorrhizal plants and diversity of species with mycorrhizal association over time (Jumpponen et al. 2002, Cázares et al. 2005, Blaalid et al. 2012).

Skeiðarársandur spans a vast area, and the nearest potential seed source is $\sim 10 \mathrm{~km}$ from the study area. Primary succession in such isolated areas is generally slow (Marteinsdóttir 2007, Marteinsdóttir et al. 2010, Makoto and Wilson 2016). Therefore, we did not expect great changes over the study period. As vegetation cover increases, with associated rise in seed production and improvement of soil conditions, successional rates will accelerate. Warming due to climate change may further speed up this process (Cannone et al. 2008).

\section{CONCLUSION}

In contrast to the traditional paradigm of deterministic processes dominating early successional stages, the assembly here was markedly stochastic but influenced by environmental factors and species availability to a spatially variable degree. Emerging spatial vegetation patterns were not simply a function of time since disturbance or substrate age. Thus, despite the apparent homogeneity of Skeiðarársandur, the species assembly is driven by different processes across the outwash plain. 
In more ameliorated conditions, environmental filtering was weaker, allowing a higher proportion of incoming seeds to establish and thereby increasing the importance of biological processes, e.g. seed limitation, in the assembly process. Thus, our results indicate that during early succession, multiple mechanisms, both stochastic and deterministic, shape the plant community assembly, with stochasticity being the main driver.

\section{ACKNOWLEDGMENTS}

We would like to thank all the field assistants that contributed to this study and the two anonymous reviewers for their constructive comments. This study was funded by Icelandic Research Fund (grants nr. 040263031 and 090255021). BM work was supported by the University of Iceland Innovation Fund. The study has been supported by the TRY initiative on plant traits (http://www.try-db.org). The TRY initiative and database is hosted, developed and maintained by J. Kattge and G. Bönisch (Max Planck Institute for Biogeochemistry, Jena, Germany). TRY is currently supported by DIVERSITAS/ Future Earth and the German Centre for Integrative Biodiversity Research (iDiv) Halle-Jena-Leipzig.

\section{Literature Cited}

Adler, P. B., A. Fajardo, A. R. Kleinhesselink, and N. J. Kraft. 2013. Trait-based tests of coexistence mechanisms. Ecology Letters 16:1294-1306.

Bernhardt-Römermann, M., C. Römermann, V. D. Pillar, T. Kudernatsch, and A. Fischer. 2010. High functional diversity is related to high nitrogen availability in a deciduous forest - evidence from a functional trait approach. Folia Geobotanica 45:111-124.

Blaalid, R., et al. 2012. Changes in the root-associated fungal communities along a primary succession gradient analysed by 454 pyrosequencing. Molecular Ecology 21:1897-1908.

Buma, B., S. Bisbing, J. Krapek, and G. Wright. 2017. A foundation of ecology rediscovered: 100 years of succession on the William S. Cooper plots in Glacier Bay, Alaska. Ecology 98:1513-1523.

Callaway, R. M. 1995. Positive interactions among plants. Botanical Review 61:306-349.

Cannone, N., G. Diolaiuti, M. Guglielmin, and C. Smiraglia. 2008. Accelerating climate change impacts on alpine glacier forefield ecosystems in the European Alps. Ecological Applications 18:637-648.

Cázares, E., J. M. Trappe, and A. Jumpponen. 2005. Mycorrhiza-plant colonization patterns on a subalpine glacier forefront as a model system of primary succession. Mycorrhiza 15:405-416.

Chang, C., and J. HilleRisLambers. 2016. Integrating succession and community assembly perspectives. F1000Research 5:2294.

Chang, L., et al. 2014. Analysis of herbaceous plant succession and dispersal mechanisms in deglaciated terrain on Mt. Yulong, China. Scientific World Journal 2014:154539.

Chapin, F. S., L. R. Walker, C. L. Fastie, and L. C. Sharman. 1994. Mechanisms of primary succession following deglaciation at Glacier Bay, Alaska. Ecological Monographs 64:149175.

Chesson, P. 2000. Mechanisms of maintenance of species diversity. Annual Review of Ecology and Systematics 31:343-366.

Connell, J. H., and R. O. Slatyer. 1977. Mechanisms of succession in natural communities and their role in community stability and organization. American Naturalist 111:11191144.

Cornelissen, J. H. C., et al. 2003. A handbook of protocols for standardised and easy measurement of plant functional traits worldwide. Australian Journal of Botany 51:335-380.

de Bello, F., et al. 2013a. Hierarchical effects of environmental filters on the functional structure of plant communities: a case study in the French Alps. Ecography 36:393-402.

de Bello, F., et al. 2012. Functional species pool framework to test for biotic effects on community assembly. Ecology 93:2263-2273.

de Bello, F., et al. 2013b. Evidence for scale- and disturbancedependent trait assembly patterns in dry semi-natural grasslands. Journal of Ecology 101:1237-1244.

del Moral, R. 2010. The importance of long-term studies of ecosystem reassembly after the eruption of the Kasatochi Island volcano. Arctic Antarctic and Alpine Research 42: 335-341.

del Moral, R., and L. C. Bliss. 1993. Mechanisms of primary succession - insights resulting from the eruption of Mount St-Helens. Advances in Ecological Research 24:1-66.

del Moral, R., and B. Magnússon. 2014. Surtsey and Mount St. Helens: a comparison of early succession rates. Biogeosciences 11:2099-2111.

del Moral, R., J. H. Titus, and A. M. Cook. 1995. Early primary succession on Mount St-Helens, Washington, USA. Journal of Vegetation Science 6:107-120.

Fitter, A. H., and H. J. Peat. 1994. The ecological flora database. Journal of Ecology 82:415-425.

Fukami, T. 2015. Historical contingency in community assembly: integrating niches, species pools, and priority effects. Annual Review of Ecology, Evolution, and Systematics 46:1-23.

Gotelli, N. J., and D. J. McCabe. 2002. Species co-occurrence: a meta-analysis of J. M. Diamond's Assembly Rules Model. Ecology 83:2091-2096.

Götzenberger, L., et al. 2012. Ecological assembly rules in plant communities - approaches, patterns and prospects. Biological Reviews 87:111-127.

Götzenberger, L., et al. 2016. Which randomizations detect convergence and divergence in trait-based community assembly? A test of commonly used null models. Journal of Vegetation Science 27:1275-1287.

Green, W. 2009. USDA PLANTS Compilation, version 1, 0902-02. (http://bricol.net/downloads/data/PLANTSdatabase/) NRCS: The PLANTS Database (http://plants.usda.gov, 1 February 2009). In L.-U. National Plant Data Center: Baton Rouge, editor.

Grime, J. P. 2006. Trait convergence and trait divergence in herbaceous plant communities: mechanisms and consequences. Journal of Vegetation Science 17:255-260.

Hempel, S., et al. 2013. Mycorrhizas in the Central European flora: relationships with plant life history traits and ecology. Ecology 94:1389-1399.

Hodkinson, I. D., S. J. Coulson, and N. R. Webb. 2003. Community assembly along proglacial chronosequences in the high Arctic: vegetation and soil development in north-west Svalbard. Journal of Ecology 91:651-663.

Jones, C. C., and R. del Moral. 2009. Dispersal and establishment both limit colonization during primary succession on a glacier foreland. Plant Ecology 204:217-230.

Jumpponen, A., J. M. Trappe, and E. Cázares. 2002. Occurrence of ectomycorrhizal fungi on the forefront of retreating Lyman Glacier (Washington, USA) in relation to time since deglaciation. Mycorrhiza 12:43-49.

Kattge, J., et al. 2011. TRY - a global database of plant traits. Global Change Biology 17:2905-2935. 
Kembel, S. W., et al. 2010. Picante: R tools for integrating phylogenies and ecology. Bioinformatics 26:1463-1464.

Kew, R. B. G. 2008. Seed Information Database (SID). Version 7.1.

Kleyer, M., et al. 2008. The LEDA Traitbase: a database of lifehistory traits of the Northwest European flora. Journal of Ecology 96:1266-1274.

Klimešová, J., and F. de Bello. 2009. CLO-PLA: the database of clonal and bud bank traits of Central European flora. Journal of Vegetation Science 20:511-516.

Kofler, K. 2004. Large scale vegetation patterns on a sandur plain: a digital vegetation map of Skeiðarársandur derived from satellite imagery. M.Sc. Thesis. University of Salzburg, Salzburg.

Kristinsson, H. 2010. Flowering plants and ferns of Iceland. Mál og menning, Reykjavík, Iceland.

Kühn, I., W. Durka, and S. Klotz. 2004. BiolFlor - a new planttrait database as a tool for plant invasion ecology. Diversity and Distributions 10:363-365.

Lavorel, S., et al. 2007. Plant functional types: Are we getting any closer to the Holy Grail? Pages 149-164 in J. G. Canadell, D. Pataki, and L. Pitelka, editors. Terrestrial ecosystems in a changing world. Springer-Verlag, Berlin, Germany.

Leishman, M. R. 2001. Does the seed size/number trade-off model determine plant community structure? An assessment of the model mechanisms and their generality. Oikos 93:294-302.

Makoto, K., and S. D. Wilson. 2016. New multicentury evidence for dispersal limitation during primary succession. American Naturalist 187:804-811.

Marteinsdóttir, B. 2007. Small scale spatial patterns and colonization proccesses in early successional environment. M.Sc. Thesis. University of Iceland, Reykjavík.

Marteinsdóttir, B., and O. Eriksson. 2014. Trait-based filtering from the regional species pool into local grasslands communities. Journal of Plant Ecology 7:347-355.

Marteinsdóttir, B., K. Svavarsdóttir, and T. E. Thórhallsdóttir. 2010. Development of vegetation patterns in early primary succession. Journal of Vegetation Science 21:531-540.

Marteinsdóttir, B., T. E. Thórhallsdóttir, and K. Svavarsdóttir. 2013. An experimental test of the relationship between small scale topography and seedling establishment in primary succession. Plant Ecology 214:1007-1015.

Mason, N. W. H., et al. 2012. Changes in coexistence mechanisms along a long-term soil chronosequence revealed by functional trait diversity. Journal of Ecology 100:678-689.

Mayfield, M. M., and J. M. Levine. 2010. Opposing effects of competitive exclusion on the phylogenetic structure of communities. Ecology Letters 13:1085-1093.

Meiners, S. J., M. W. Cadotte, J. D. Fridley, S. T. A. Pickett, and L. R. Walker. 2014. Is successional research nearing its climax? New approaches for understanding dynamic communities. Functional Ecology 29:154-164.

Miller, E. T., D. R. Farine, and C. H. Trisos. 2017. Phylogenetic community structure metrics and null models: a review with new methods and software. Ecography 40:461-477.

Mori, A. S., M. Uchida, and H. Kanda. 2013. Non-stochastic colonization by pioneer plants after deglaciation in a polar oasis of the Canadian High Arctic. Polar Science 7:278-287.

Mouchet, M. A., S. Villéger, N. W. H. Mason, and D. Mouillot. 2010. Functional diversity measures: an overview of their redundancy and their ability to discriminate community assembly rules. Functional Ecology 24:867-876.

Mouquet, N., et al. 2012. Ecophylogenetics: advances and perspectives. Biological Reviews 87:769-785.

Pärtel, M., R. Szava-Kovats, and M. Zobel. 2011. Dark diversity: shedding light on absent species. Trends in Ecology and Evolution 26:124-128.
Pavoine, S., and M. Bonsall. 2011. Measuring biodiversity to explain community assembly: a unified approach. Biological Reviews 86:792-812.

Perronne, R., F. Munoz, B. Borgy, X. Reboud, and S. Gaba. 2017. How to design trait-based analyses of community assembly mechanisms: insights and guidelines from a literature review. Perspectives in Plant Ecology, Evolution and Systematics 25:29-44.

Raevel, V., C. Violle, and F. Munoz. 2012. Mechanisms of ecological succession: insights from plant functional strategies. Oikos 121:1761-1770.

Scheffer, M., and E. H. van Nes. 2006. Self-organized similarity, the evolutionary emergence of groups of similar species. Proceedings of the National Academy of Sciences of the United States of America 103:6230-6235.

Schleicher, A., C. Peppler-Lisbach, and M. Kleyer. 2011. Functional traits during succession: is plant community assembly trait-driven? Preslia 83:347-370.

Schleuter, D., M. Daufresne, F. Massol, and C. Argillier. 2010. A user's guide to functional diversity indices. Ecological Monographs 80:469-484.

Shipley, B. 1993. A null model for competitive hierarchies in competition matrices. Ecology 74:1693-1699.

Spasojevic, M. J., and K. N. Suding. 2012. Inferring community assembly mechanisms from functional diversity patterns: the importance of multiple assembly processes. Journal of Ecology 100:652-661.

Stefánsson, S. 1948. Flóra Íslands. Hið Íslenska Náttúrufræðifélag, Reykjavík, Iceland.

Swenson, N. G., and B. J. Enquist. 2009. Opposing assembly mechanisms in a Neotropical dry forest: implications for phylogenetic and functional community ecology. Ecology 90:2161-2170

Swenson, N. G., B. J. Enquist, J. Pither, J. Thompson, and J. K. Zimmerman. 2006. The problem and promise of scale dependency in community phylogenetics. Ecology 87:2418-2424.

Titus, J. H., and R. del Moral. 1998. Seedling establishment in different microsites on Mount St. Helens, Washington, USA. Plant Ecology 134:13-26.

Turnbull, L. A., M. Rees, and M. J. Crawley. 1999. Seed mass and the competition/colonization trade-off: a sowing experiment. Journal of Ecology 87:899-912.

Ulrich, W., et al. 2014. Soil conditions and phylogenetic relatedness influence total community trait space during early plant succession. Journal of Plant Ecology 7:321-329.

Ulrich, W., et al. 2016. Species interactions and random dispersal rather than habitat filtering drive community assembly during early plant succession. Oikos 125:698-707.

van der Maarel, E. 1979. Transformation of cover-abundance values in phytosociology and its effects on community similarity. Vegetatio 39:97-114.

Vilmundardóttir, O. K., G. Gísladóttir, and R. Lal. $2015 a$. Between ice and ocean; soil development along an age chronosequence formed by the retreating Breiðamerkurjökull glacier, SE-Iceland. Geoderma 259-260:310-320.

Vilmundardóttir, O. K., G. Gísladóttir, and R. Lal. 2015b. Soil carbon accretion along an age chronosequence formed by the retreat of the Skaftafellsjökull glacier, SE-Iceland. Geomorphology 228:124-133.

Violle, C., and L. Jiang. 2009. Towards a trait-based quantification of species niche. Journal of Plant Ecology 2:87-93.

Walker, L. R., and R. del Moral. 2003. Primary succession and ecosystem rehabilitation. Cambridge University Press, Cambridge, UK.

Walker, L. R., and R. del Moral. 2009. Lessons from primary succession for restoration of severely damaged habitats. Applied Vegetation Science 12:55-67. 
Walker, L. R., E. Velázquez, and A. B. Shiels. 2009. Applying lessons from ecological succession to the restoration of landslides. Plant and Soil 324:157-168.

Webb, C. O., D. D. Ackerly, M. A. McPeek, and M. J. Donoghue. 2002. Phylogenies and community ecology. Annual Review of Ecology and Systematics 33:475-505.

Weiher, E., and P. A. Keddy. 1995. Assembly rules, null models, and trait dispersion - new questions from old patterns. Oikos $74: 159-164$.
Zaplata, M. K., et al. 2013. Species-driven phases and increasing structure in early-successional plant communities. American Naturalist 181:E17-E27.

Zhang, H., et al. 2015. Using functional trait diversity to evaluate the contribution of multiple ecological processes to community assembly during succession. Ecography 38:1176-1186.

Zillio, T., and R. Condit. 2007. The impact of neutrality, niche differentiation and species input on diversity and abundance distributions. Oikos 116:931-940.

\section{SUPPORTING INFORMATION}

Additional supporting information may be found in the online version of this article at http://onlinelibrary.wiley.com/doi/ 10.1002/ecy.2079/suppinfo 